turn in the last part of his career to the ethology of man. In the 1960s, Desmond Morris's The Naked Ape and Lorenz's On Aggression - both engaging, if flawed, books - had thrown open the whole debate about the extent to which present-day human behaviour can be explained in terms of our evolutionary past. If our evolutionary history provides explanations, perhaps it also provides clues to the treatment of dysfunctional or abnormal human behaviour.

Tinbergen's venture into this area did not attract widespread support. His work, with his wife Lies, on the ethology of childhood autism was seen by many as too anecdotal and simplistic, and his Nobel lecture, in which he talked about both autism and the rather wacky Alexander technique for improving body posture, would, in the words of Kruuk "be best forgotten".

In addition to his comprehensive account of Tinbergen the scientist, Kruuk also discusses Tinbergen the man. He offers insights into Tinbergen's relationships with his wife and children, his siblings, including his older brother Jan, who won a Nobel Prize for economics in 1969, and with his students and colleagues. Kruuk also discusses in detail the recurrent depression that afflicted Tinbergen, especially during the last 20 years of his life, which impaired his capacity for work.

Kruuk succeeds in conveying the complexity of Tinbergen's personality. Tinbergen was self-effacing, modest and charming, totally without pomposity, haunted by selfdoubt, but was at the same time demanding of himself and others, ambitious, charismatic and a natural showman and leader. He was legendary for his rigorous powers of analysis (all of us who participated in his weekly seminars have our own favourite stories of his clinical dissection of any hapless speaker with leaky intellectual plumbing), but he often relied on intuition and creative leaps in drawing conclusions.

What of his lasting contribution to science? Where has ethology gone since Tinbergen's death? Some of the people Kruuk quotes think it is "as alive and strong as ever", whereas others say it has evolved into behavioural ecology and animal cognition.

The prognosis offered some 20 years ago by Robert Hinde in his Niko Tinbergen lecture is more inclusive. He argued that the lasting influence of ethology, and therefore of Tinbergen's work, would be felt by the interaction of its ideas and approaches with many other fields, such as anthropology, neuroscience, psychiatry, psychology, evolution and ecology. It is now widely accepted that it is possible to analyse the behaviour of animals in their natural environment with rigour and precision. Niko showed us how to do it.

John Krebs is in the Department of Zoology,

University of Oxford, South Parks Road,

Oxford OX1 3PS, UK.

\section{Chemistry's bag of tricks}

\section{From Elements to Atoms: \\ A History of Chemical Composition (Transaction 92-4) \\ Robert Siegfried \\ American Philosophical Society: 2003. \\ 278 pp. $\$ 24$ \\ Bernadette Bensaude-Vincent}

As a scholar for more than 40 years, Robert Siegfried says he has witnessed the emergence of the history of science as an academic specialty, and would like to see it included in the scientific curriculum. With such didactic purposes in mind, he deliberately runs counter to the current historiographical mainstream.

Siegfried's view is that chemistry evolved from a metaphysical idea of composition into an experiential, positive idea of composition, forged by AntoineLaurent Lavoisier and completed by John Dalton's atomic theory. In so doing, Siegfried advocates a positivistic view that has been heavily criticized by a generation of historians of science. He also purposefully writes history from a presentday perspective.

On top of that, he focuses on the chemists' philosophy of matter, even though the interest of many historians shifted long ago from concepts to practices and the social dimensions of science. He quotes several recent historical studies of the same period, but never engages in historiographical debates. This is "my story", he claims, just one interpretation among many others. In his view, history is "a bag of tricks that we play on the dead".

But despite his old-fashioned approach, Siegfried's account of eighteenth-century chemistry is not too dissimilar from other recent descriptions. Like Frederic L. Holmes in his book Eighteenth-century Chemistry as an Integrative Enterprise (University of California, 1989), he stresses the importance of salt chemistry, which provided the empirical core of modern chemistry. And like Ursula Klein (Science in Context 7, 163; 1994), he assumes that analysis and synthesis played a key role in the emergence of an empirical concept of composition. He agrees with most historians of chemistry that combustion was not the major issue discussed in the eighteenth century, and that phlogiston theory was by no means the overarching doctrine that dominated all chemical works before Lavoisier. In fact, it only really became a theoretical framework when chemists started investigating dozens of 'airs' in the 1770s.

In other words, Siegfried does not read eighteenth-century chemistry 'backwards' as an empty period preparing the stage for Lavoisier's chemical revolution. Instead, he provides a fine and nuanced account of many of the achievements that pre-dated

Lavoisier, such as the measurement by Torbern Bergman of the relative quantities of phlogiston in metals.

Even so, Siegfried's choice of a present-day perspective distorts this penetrating and thoughtful insight into chemistry's past. How relevant is a historical narrative that focuses on the absence of what would emerge later? In this book, Siegfried repeatedly points out what was lacking - a clear distinction between concepts, and a clear notion of what chemical substances are - and traces anticipations and prefigurations of notions that would only be explicit by Lavoisier or Dalton. Wouldn't it be more useful for students to try to understand how chemists of the past constructed their own views and notions? But Siegfried assumes that chemists before Lavoisier had no theory of their own, no coherent system and were philosophically inconsistent, thereby encouraging the view of a theory-free experimental practice that sounds at odds with the project of describing exclusively their philosophical notions.

Siegfried's assumption that "chemical composition has had no fundamental conceptual change" since Lavoisier and Dalton suggests that there is no history of chemical atomism since Dalton's atomic theory. Furthermore, the book's title, From Elements to Atoms, suggests that the idea of the element is now obsolete and that modern chemistry focuses exclusively on the atom. This is a view that many chemistry teachers will no doubt debate.

Bernadette Bensaude-Vincent is in the Department of Philosophy, Université de Paris X, 92001 Nanterre Cedex, France. 